\title{
Embodied fortitude: An introduction to the Finnish construct of sisu
}

\author{
Emilia Lahti
}

\begin{abstract}
In the Nordic country of Finland, a cultural construct known as sisu has been used for centuries to describe the enigmatic power that enables individuals to push through unbearable challenges. Sisu, however, lacks a direct translation and the construct has remained poorly defined and understudied. This article seeks to answer the question "What is sisu?" through the thematic analysis of two sets of qualitative data $(n=500$ and $n=569)$ that were collected as part of a survey $(\mathrm{N}=1,208)$ among a sample group of primarily Finnish respondents. The most prominent part of the conceptual core of sisu is the ability to surpass one's preconceived limitations by accessing stored-up energy reserves. Sisu is invoked by adversity and is more about finding energy in the moment than about long-term endurance, goal-setting and achievement. Instead of being about conscious willing or mental fortitude, it implies a strength that is connected to the visceral and somatic dimension of human endurance. I propose that sisu points to a universal phenomenon of latent energy in the human system, lends it a name and contributes toward a more culturally rich conversation on the human experience of overcoming adversity across life challenges.
\end{abstract}

Keywords: sisu, positive psychology, embodied cognition, qualitative research, thematic analysis, Finland

\section{Introduction}

Adversities are an inherent part of the fabric of human existence. Consequently, our ability to overcome hardships and take action against slim odds has always been crucial for the survival of our species, as well as for the development of modern society. Over 100 years ago, the founder of American psychology, William James (1914), outlined the need for a more nuanced understanding of human endurance and the need for "a topography of the limits of human power" (p. 38). In addition to taking strides in understanding mental illness and the causes of disease within individuals, researchers have expanded the conceptual landscape of psychology and developed empirically sound practices to understand the conditions and psychological resources that individuals draw from during times of distress. Within the past two decades, our understanding has become enriched with theories relating to concepts such as post-traumatic growth (Ramos \& Leal, 2013; Tedeschi \& Calhoun, 2004), grit (Duckworth, Peterson, Matthews, \& Kelly, 2007), resilience (Luthar, Cicchetti, \& Becker, 2000), mental toughness (Gucciardi, Gordon, \& Dimmock, 2009; Jones, Hanton, \& Connaughton, 2007), courage (Pury \& Lopez, 2009; Pury, Kowalski, \& Spearman, 2007), and hardiness (Kobasa, 1979; Maddi, 2004, 2006). While the world is safer than it has even been in our recorded history and individuals experience more wellbeing (Pinker, 2011), conflict and adversity still remain an inseparable part of life. Gaining a more nuanced understanding of what enables individuals to endure hardships is not only useful,

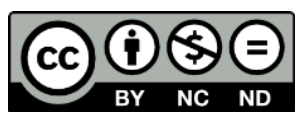

Copyright belongs to the author(s) www.internationaljournalofwellbeing.org 
but is, in fact, necessary. However, the majority of the constructs currently used in examining these phenomena are mostly derived from the North American research tradition, therefore contributing to a discussion that is culturally unbalanced and not representative of the human family as a whole.

Bermant, Talwar, and Rozin (2011) have urged practitioners within the field of positive psychology to be careful not to imitate psychology, with its focus on American culture, but to pay attention to other cultures and the social context of the human related phenomena they research. Prior to this, Peterson (2008) wrote that, "There are lessons to be learned in all cultures about what makes life worth living and no language has a monopoly on the vocabulary" (para. 3). More recently, in the interest of adding to a greater cross-cultural sensitivity within the research around wellbeing, Lomas (2016) outlined the beginnings of a positive cross-cultural lexicography of "untranslatable" words pertaining to wellbeing that do not have a direct English translation. Sisu is one of the 216 words Lomas mentions, and attributes the research on sisu as the inspiration for the lexicography (Anthes, 2016; Lomas, 2016).

Sisu is an age-old Finnish cultural construct traditionally used to describe the ability of individuals to push through unbearable challenges. It has been researched in the context of Finnish ethnic heritage among second- and later-generation Finnish Americans (Aho, 1994; Taramaa, 2009), as an ethnic symbol in constructing and maintaining Finnish American culture (Palo Stoller, 1996; Susag, 1998), in the literary production of "Finnishness" within Finnish American authors (Taramaa, 2007), and, for example, as part of underground iron ore miners' occupational narratives (Lucas \& Buzzanell, 2004). Sisu, however, lacks a direct translation (Aho, 1994; Lucas \& Buzzanella, 2004) and has been described in vague terms such as "inner fire" and "superhuman nerve force" (Strode \& Hinshaw as cited in Aho, 1994; Taramaa, 2007).

Etymologically, the word sisu derives from the word sisus, which refers to the internal organs of a human or animal body (literally, the guts), or it can mean the interior of an object. Dating back to the $16^{\text {th }}$ century, when the first written remarks about sisu occurred, the word referred to a quality or inherent tendency. In 1745, Daniel Juslenius defined sisucunda in his dictionary as the location in the human body where strong affects originate (Länsimäki, 2003). In Estonian, sisu still means the inner part or content, whereas in the Finnish language it evolved to describe a character trait. Sisu originally referred to a negative quality, as the word pahansisuinen [bad spirited] implies. The transition of sisu into a positive quality and national narrative was partially backed by the Finnish long distance running success in the late $19^{\text {th }}$ and early $20^{\text {th }}$ centuries. During the Winter War in 1939-1940, sisu was lifted to an elevated status because of Finland's miraculous opposition to the mammoth-size Red Army. In 1940, The New York Times ran a story entitled, "Sisu: A Word That Explains Finland" (Strode, 1940) and Time Magazine ("Finland: Nothing Worse to Fear," 1943) described sisu "as a peculiarly Finnish brand of doggedness, capable of facing down death itself."

Despite being an integral part of the Finnish culture and folklore, sisu has remained understudied and elusive. When I first took a closer look at sisu at the end of 2012, I found no empirical research that would have sought to understand sisu in its own right, there were few online publications on the topic providing insight into it, and the construct lacked a coherent definition. In fact, many Finns themselves seemed to find it difficult to explain sisu. There has been debate over whether sisu is a character trait, tendency, national spirit (Aho, 1994), or merely a myth (Hintikka, 1998). Slade Lander (1991) argued that the time for sisu is over and it is no longer part of Finnish characteristics. In 1994, Aho concluded that "It should be clear by now that we do need a good deal of organized, systematic scientific research to discover the scope and depth of sisu, geographically and situationally" (p. 199). Due to lack of existing systematic 
research on sisu and the elusiveness around the construct, the research question I begin with in this preliminary study is simply "What is sisu?" This is followed by an inquiry into whether or not sisu is a positive quality to have.

\section{Method}

\subsection{Participants and procedure}

Participants were invited to take part in the survey through social media sites such as Twitter and Facebook. No paid crowdsourcing services were used, but the survey spread organically. The average age of the respondents was 42 years (SD 12.5), and $80 \%$ were women and $95 \%$ Finnish. ${ }^{1}$

Prior to commencing, the study received ethical approval from the University of Pennsylvania Institutional Review Board. The survey tracking the representations of sisu among Finns and those familiar with the construct was created using Qualtrics and made available in Finnish and English. The respondents $(N=1,208)$ were given the choice not to answer every question, so the number of responses for each question varied. To answer the main research question about the nature of sisu, answers to two open-ended qualitative questions were analysed. They consisted of 500 answers to ("How would you define 'sisu'?") and 569 answers ("What consequences there may be of having too much sisu?"). The latter question was presented to respondents who had replied "yes" to the previous multiple-choice question "Can an individual have too much sisu?" Given the historical and cultural tendency in Finland to glorify sisu, the second question aimed to provide another angle on the construct, focusing on its potential downside.

\subsection{Theoretical background}

For conducting a descriptive qualitative analysis, thematic analysis (TA) was chosen. Braun and Clarke (2006, p. 76) describe TA as "a method for identifying, analysing, and reporting patterns (themes) within the data." Rather than merely organising the data, it is often used to interpret various aspects of the research topic and is particularly useful when little is known about the topic under study (Boyatzis, 1998). While content analysis is a well-suited method for analysing large quantities of qualitative data (Namey, Guest, Thairu, \& Johnson, 2007) it was abandoned in favour of TA, which goes beyond word or phrase counting to analyses involving "identifying and describing both implicit and explicit ideas" (Guest, MacQueen, \& Namey, 2012, p. 10). Importance of a theme does not necessarily depend on quantifiable measures, but rather on "whether it captures something important in relation to the overall research question" (Braun \& Clarke, 2006, p. 82). Analysing the content of the data for recurrence of words or topics is suitable for simple reporting of common issues mentioned in data (Green \& Thorogood, 2004), whereas TA offers a tool for more sophisticated and rich, yet complex, account of the data (Braun \& Clarke, 2006).

In the past, TA has suffered from a lack of clear guidelines. Attride-Stirling (2001) notes that this has contributed to some researchers not indicating how they actually arrived at their conclusions. To address this concern, a six-phase guide for conducting TA in a way that employs a clear, replicable, and transparent methodology outlined by Braun and Clarke (2006) was applied. The phases are: familiarisation with data, generating initial codes, searching for themes among codes, reviewing themes, defining and naming themes, and producing the final report.

\footnotetext{
${ }^{1}$ Demographic information was requested at the end of the survey and is based on information provided by those respondents $(n=1,018)$ who provided it. For informed consent and list of questions, see appendices $\mathrm{A}$ and $\mathrm{B}$.
} 
As Braun and Clarke (2006) instructed, one can code the content of the entire data set, or code to identify particular (and possibly limited) features of the data set. Both data sets were analysed using the six-phase guide outlined by Braun and Clarke (2006).

\subsection{Data analysis}

The data were first read through twice to get an overall sense of the scope and flavour. Interesting ideas and repeating patterns were written down. After the immersion phase, semantic content was identified (Braun \& Clarke, 2006) and the data were initially coded for organising into groups that are potentially meaningful in relation to the phenomena (Braun \& Clarke, 2006; Tuckett, 2005). The codes identified features of the data that were considered relevant to the research question. A "good code" captures the qualitative richness of the phenomena (Boyatzis, 1998 , p. 1). Due to the high volume of responses, the data in both cases were coded until theoretical saturation was reached (Fusch \& Ness, 2015; Guest, Bunce, \& Johnson, 2006) and analysing it further did not produce leads for themes, and the core categories had become sufficiently dense. Unearthing ideas and interesting bits was data driven (Braun \& Clarke, 2006) as a result of the researcher following an inductive process of coding the data without trying to fit them into a pre-existing coding frame. Memoing is part of qualitative research (Miles \& Huberman, 1984) and was done throughout the process of collecting and reflecting on the data.

The third stage involved sorting and combining different codes into clusters of similar meaning, ultimately leading to finer and more detailed thematic granularity. The process was continuous and iterative. Potential themes were traced with the help of preliminary labels previously attached to the data. Attention was paid not only to emergent themes but also data that diverged from the emerging patterns. This included anything that seemed to carry some kind of a relationship to another code. For example, the qualitative data around the question "What is sisu?" resulted in several divergent descriptions of enduring hardship. Regardless of their intensity or nature, these answers were all initially coded as "enduring adversity." After a more thorough analysis, several of the codes were moved under a more specific code of "enduring extreme adversity."

While digital applications were used as a tool for the analysis, at this stage, Braun and Clarke's (2006) recommendation to visualise the data proved to be helpful. It meant creating an old-school image board that contained all the original code names and manually categorising them into clusters of notes. This was useful for gaining a clearer understanding of the semantic code jungle, observing potential links, and sorting codes into different candidate themes and subtheme piles. Candidate themes were later evaluated for inner coherence, as well as in relation to relevant qualitative data, so that repeated patterns within the broader entity could emerge and be combined into categories of most prominent narratives reflecting the commonly underlying themes on sisu.

At this point, all the data that were too thin and not supported by the overall narrative were discarded. After a comprehensive description of data through the use of themes, the analysis moved to refining and communicating the story of the themes as separate blocks of knowledge, but also in relation to the overall material. A descriptive name for each theme was created. Finally, for the purpose of presenting the results, short and nuanced excerpts were selected and incorporated into one single table. 


\section{Findings}

\subsection{The essence of sisu}

Five hundred answers were analysed following the previously outlined process. They produced 95 initial codes, which were organised into 11 main categories. Ultimately, three key themes with a distinct central organising concept (Braun \& Clarke, 2016) depicting the most pronounced qualities of the construct were identified (Figure 1). The final themes were: (theme 1) endurance amidst significant adversity with the emphasis on exceeding one's preconceived capacities, (theme 2) taking action against all odds and having a consistent, courageous and forward-moving approach towards challenges, and (theme 3) accessing latent inner resources of energy and endurance that have previously been unexpressed or remained unknown to the individual. Each theme included two subthemes that elaborate on the main theme. The main themes were also evaluated for their ability to describe the phenomena itself, as opposed to describing their observable outcomes. The first two, "extraordinary perseverance" and "action mindset," offered a window into the latter, while "latent power" appears to underlie the first two categories.

\section{Figure 1. The essence of sisu: Themes and subthemes}

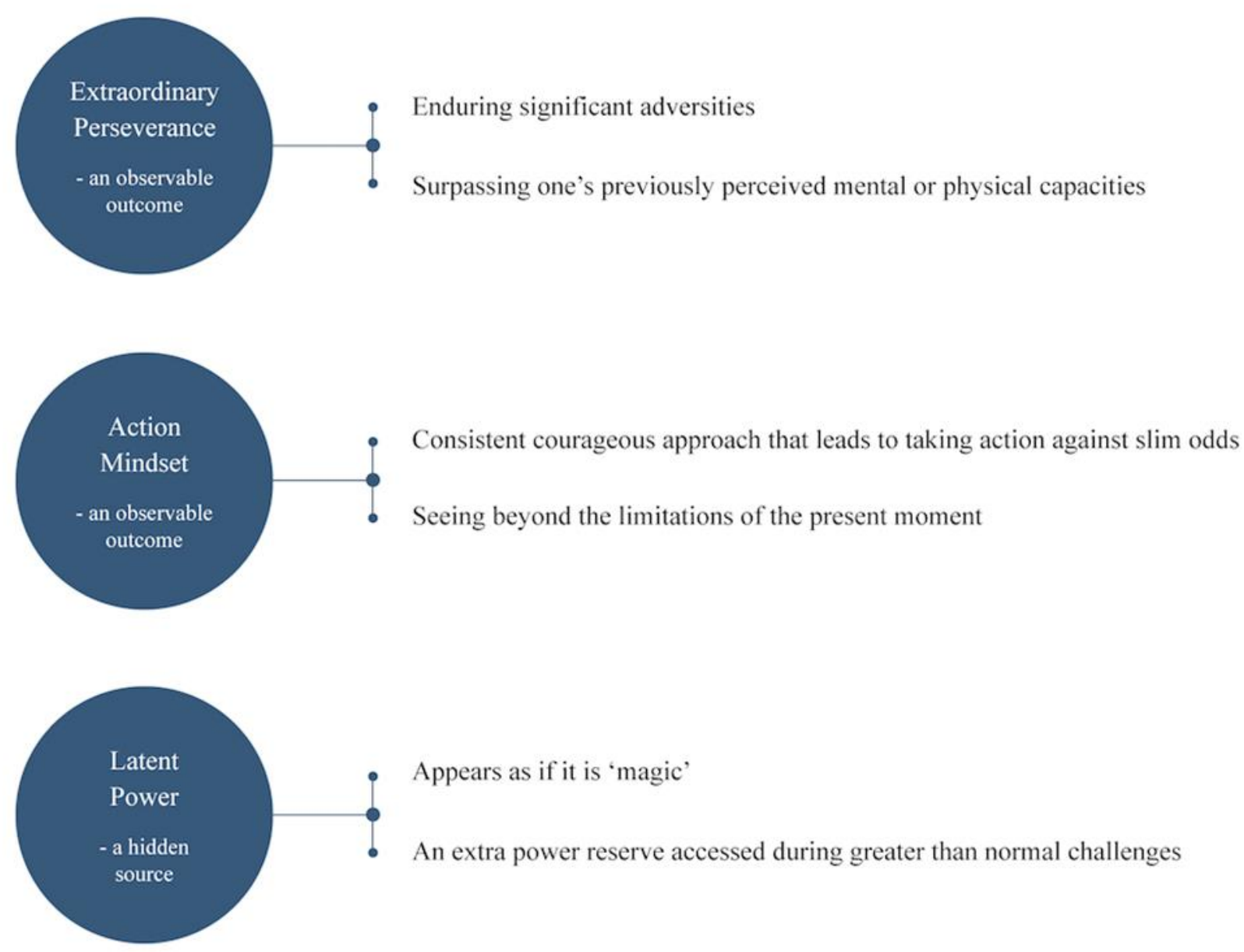

Theme 1. Extraordinary perseverance. Extending oneself during a moment of suffering or significant discomfort was one of the most pronounced themes in the data (Table 1 below). It is endurance with the emphasis on exceeding one's preconceived capacities. Sisu was mentioned in reference to overcoming hardships one has no control over, but also to describe self-selected challenges such 
as demanding athletic performances, academic endeavours, or standing up for what is right. Half of the data coded for adversity specified that sisu is about enduring significant adversity in particular (i.e., trauma, illness, accidents, loss of a loved one, functioning against very slim odds). The following descriptions exemplify the subthemes of adversity and exceeding one's preconceived capacities: "Pressing onward when you feel you cannot keep going, reaching beyond your limit, having resoluteness when facing an insurmountable obstacle, and sticking to your word," and "Blood and guts to go through the shit that life heaves on your shoulders, whether it's wars, disabling accidents or diseases, financial ruination, death of loved ones, divorce, or having to turn a swamp into productive farmland."

Respondents rarely mentioned sisu in relation to small daily nuisances. Rather, it seemed to be reserved for major disruptions, and the most commonly used words referred to significant hardships and stress. Vaikeus [adversity], epätoivon hetki [moment of desperation], este [barrier], koettelemus [tribulation], and taakka [burden] made up the majority of the references that related to enduring hardship. The word haaste [challenge, tribulation] perhaps carrying a more positive tone of striving towards a goal was used rarely, and even then it was often accompanied by ylitsepääsemätön [unbearable]. A majority of the data coded for extraordinary perseverance included the phrase "to not give up" [periksiantamattomuus, olla antamatta periksi], as opposed to using a similar expression with a somewhat different semantic flavour: "to keep on going" [ jatkaa eteenpäin].

Table 1. The essence of sisu: Codes and examples for extraordinary perseverance

\begin{tabular}{|c|c|c|}
\hline $\begin{array}{l}\text { Extraordinary } \\
\text { perseverance } \\
\text { To endure and remain } \\
\text { resolute amidst } \\
\text { significant adversities, } \\
\text { surpass one's } \\
\text { preconceived mental or } \\
\text { physical capacities and } \\
\text { hold oneself } \\
\text { accountable for high } \\
\text { standards. }\end{array}$ & $\begin{array}{l}\text { 1.1 Not giving up } \\
\text { 1.2 Finishing what one starts } \\
\text { 1.3 Enduring adversity } \\
\text { 1.4 Exceeding oneself } \\
\text { 1.5 Doing the impossible } \\
\text { 1.6 Having integrity } \\
\text { 1.7 Not taking short-cuts } \\
\text { at the expense of } \\
\text { quality of effort }\end{array}$ & $\begin{array}{l}\text { "Sisu to me refers to the strength that lies beyond } \\
\text { perceived limitations. Sisu exists within everyone } \\
\text { and is usually stumbled upon when one faces } \\
\text { insurmountable adversity." } \\
\text { "It's running the marathon after the } 35 \mathrm{~K} . " \\
\text { "Sisu means not giving up even when the obstacles } \\
\text { seem insurmountable. It means pushing on and } \\
\text { persisting even when things get tough." } \\
\text { "Sisu is a capability to extract the (remaining) } \\
\text { reserves of willpower or physical power when } \\
\text { without it one would give up or accept a less } \\
\text { complete outcome." } \\
\text { "Sisu is never giving up, fighting until the end and } \\
\text { then beyond. Beating the odds, achieving what no } \\
\text { one thought possible." }\end{array}$ \\
\hline
\end{tabular}

Theme 2. Action mindset. Descriptions coded under the theme action mindset ${ }^{2} \operatorname{display}$ a type of consistent, courageous approach towards challenges (Table 2 below). It is to have a tendency to lean into the unknown and even seek out situations that are likely to test the individual. The theme is about taking action when there is no guarantee of success, and, in fact, failure may seem

\footnotetext{
2 Jonathan Gosling and Henry Mintzberg (2003) have used the term in a different sense as part of their framework for leadership training. It is one of a set of five managerial mindsets they describe to refer to attunement in managing change.
} 
the likely outcome. It is about the beliefs and mindsets that pave the way towards action in situations that may at first seem overpowering and impossible. In this sense, it can even be seen as a catalyst for exceeding our preconceived capacities. Sisu is about "sticking to what is right whether it makes you popular or not. Believing in what you do no matter what the majority thinks," as one respondent wrote. "A belief that, if you persist and stay the course, the outcome will be ultimately good," is an example by another participant. If extraordinary perseverance relates to surpassing ourselves during the literal and proverbial ultra marathons of life, action mindset means taking the first step to embark on a journey that is likely to test our known capacities.

Table 2. The essence of sisu: Codes and examples for action mindset

\begin{tabular}{|c|c|c|}
\hline $\begin{array}{l}\text { Action mindset } \\
\text { A consistent, } \\
\text { courageous approach } \\
\text { toward challenges, } \\
\text { taking action against } \\
\text { slim odds and not being } \\
\text { bounded by the } \\
\text { observed limitations of } \\
\text { the present moment. }\end{array}$ & $\begin{array}{l}\text { 1.8 Boldness } \\
\text { 1.9 Facing one's fears } \\
\text { 1.10 Standing up } \\
\text { 1.11 Creativity as a result } \\
\text { of hardship } \\
\text { 1.12 To believe in oneself } \\
\text { 1.13 To have guts }\end{array}$ & $\begin{array}{l}\text { "I think it's non-delusional fearlessness toward what } \\
\text { would otherwise be a difficult/frightening situation } \\
\text { as well as a belief that, if you persist and 'stay the } \\
\text { course' the outcome will be ultimately good." } \\
\text { "The ability to go against the stream." } \\
\text { "Trust in one's abilities and strength in physically or } \\
\text { mentally adverse situations." } \\
\text { "Sisu to me refers to the strength that lies beyond } \\
\text { perceived limitations. I believe that Sisu can also be } \\
\text { cultivated by developing an unwavering positive } \\
\text { mental attitude." } \\
\text { "[Sisu means] to have faith in oneself, in } \\
\text { opportunities and action." }\end{array}$ \\
\hline
\end{tabular}

Theme 3. Latent power. The theme speaks of the hard-to-explain and elusive dimension of sisu. Recurring themes were those of sisu as emotional or physical strength that emerges as we refuse to give up. Sisu as a latent inner power and capacity is about tapping into our potential dormant resources of energy and endurance that are somewhere "deep inside." An excerpt from the data:

We all hear or read about the most difficult situations humans face, like the Holocaust. And we don't really know how we would react and/or survive. When we face these personal questions of human limits, sisu has a meaning. It's the meaning that somewhere deep inside yourself lies the potential quality of individual perseverance ... it's a faith that if times get tough, you'll have the sisu to see you through.

The respondents' language in this category was rather descriptive, as if trying to explain something that sits slightly beyond the grasp of verbal expression: "I like to think of the contrast between wonder bread [white bread] and Finnish rye bread [this standing in for sisu]. I think of it as a certain type of mind/body courage. Very intuitive, has something of the 'stick to your guts' in it, and some grace," and "It is like the Japanese concept of Wabi-Sabi. You only know it to experience it." The narratives below in Table 3 suggest something hidden and powerful, which is revealed under stress that is significant enough. 
Table 3. The essence of sisu: Codes and examples for latent power

\begin{tabular}{|c|c|c|}
\hline $\begin{array}{l}\text { Latent power } \\
\text { An inner power } \\
\text { potential that exists in } \\
\text { every human being and } \\
\text { can be accessed when } \\
\text { we have consumed our } \\
\text { preconceived mental or } \\
\text { physical capacities. At } \\
\text { the heart of action that } \\
\text { manifests as } \\
\text { perseverance, courage } \\
\text { and determination. } \\
\text { More visceral and } \\
\text { somatic than cognitive } \\
\text { and conscious. }\end{array}$ & $\begin{array}{l}\text { 1.14 An innate quality } \\
\text { 1.15 In the moment } \\
\text { 1.16 Magic } \\
\text { 1.17 A spare tank of power } \\
\text { 1.18 Listless strength } \\
\text { 1.19 Transformation } \\
\text { 1.20 The second wind }\end{array}$ & $\begin{array}{l}\text { "A resolute inner force or energy to achieve a goal." } \\
\text { "Resoluteness and power that springs from deep } \\
\text { within." } \\
\text { "A mind-boggling power that allows you to try one } \\
\text { more time, even though you're physically or } \\
\text { mentally wiped out." } \\
\text { "Sisu is an inner spirit, grit, guts, determination, and } \\
\text { perseverance in the face of adversity. It's what } \\
\text { defines us, and is almost like magic in the sense that } \\
\text { with it you can do what others think is not possible." } \\
\text { "Is the fire that does not fade, no matter what. A } \\
\text { driving force, deep inside ones soul, big strong feisty } \\
\text { energy that makes one go on pursuing the set goal." }\end{array}$ \\
\hline
\end{tabular}

\subsection{Is having sisu always a good thing?}

Sisu was approached from a different vantage point in a question that examined whether sisu is always the desirable approach. An open-ended follow-up question ("What do you think are the consequences of having too much sisu?") was presented to respondents who, in a previous question, had indicated that it is possible for an individual to have too much sisu. Coding the data $(n=569)$ produced 69 initial codes that ultimately resulted in three key themes and six subthemes (Figure 2 below). The main themes were: (theme 1) sisu that is harmful to the individual, (theme 2) sisu that harms the individual's environment, and (theme 3) sisu that impairs the individual's ability to think and reason. The last mentioned was originally a subtheme of "harm to self," but because of its prominence in the data and ripple-like impact on the two previously mentioned themes, it was added as a main theme.

Theme 1. Harm to self. The subthemes outline negative physical and mental consequences to the individual, such as health problems due to constantly overextending oneself, accidents, injuries, burnout, and even death. While the public discourse at large glorifies mental strength and perpetuates the "faster, higher and stronger" mentality, the answers here displayed an alternative, critical view (Table 4). "[Too much sisu leads to] denying the realities of life, as well as the limits of human strength, therefore denying the very core of our humanity in ourselves and others," as one respondent wrote. Harm in this category also meant taking more responsibility than one can bear and making foolish or outright "stupid" sacrifices, as the following excerpt from one respondent demonstrates:

If the person has very unrealistic assumptions of mental or physical reserves, too much sisu can lead to foolhardiness and a backlash. Overtaxing mental reserves may cause mental trauma, foolhardiness in the physical domain can even cause death.

Theme 2. Harm to others. While resoluteness can be a positive driving force, there was a concern that people with too much sisu may get lost in the importance of their own personally 
experienced purpose. This could potentially lead to mercilessness towards others and inability to attune to their needs. The examples included obsession over a task at the expense of others, ignoring people's perspectives, failing to sympathise with their struggles, as well as being cold and ruthless toward one's colleagues, family and friends. Below are two examples. The codes, together with more excerpts from the data, are presented in Table 5 below.

Creativity, sadly, is a rare companion to sisu. A person with sisu is someone who is trustworthy and seeks to make it on their own at all times. They are not necessarily the most helpful person because they think everyone else is capable of making it if they only bother to try and have the will.

Arrogance, aggressive behavior. Bullying. Overly critical of others. Too much [sisu] makes a person intimidating to others, thus cultivating disrespect amongst peers. A person possessing sisu must also possess grace and kindness. It is a fine line to walk.

\section{Figure 2. Consequences of having too much sisu: Themes and subthemes}
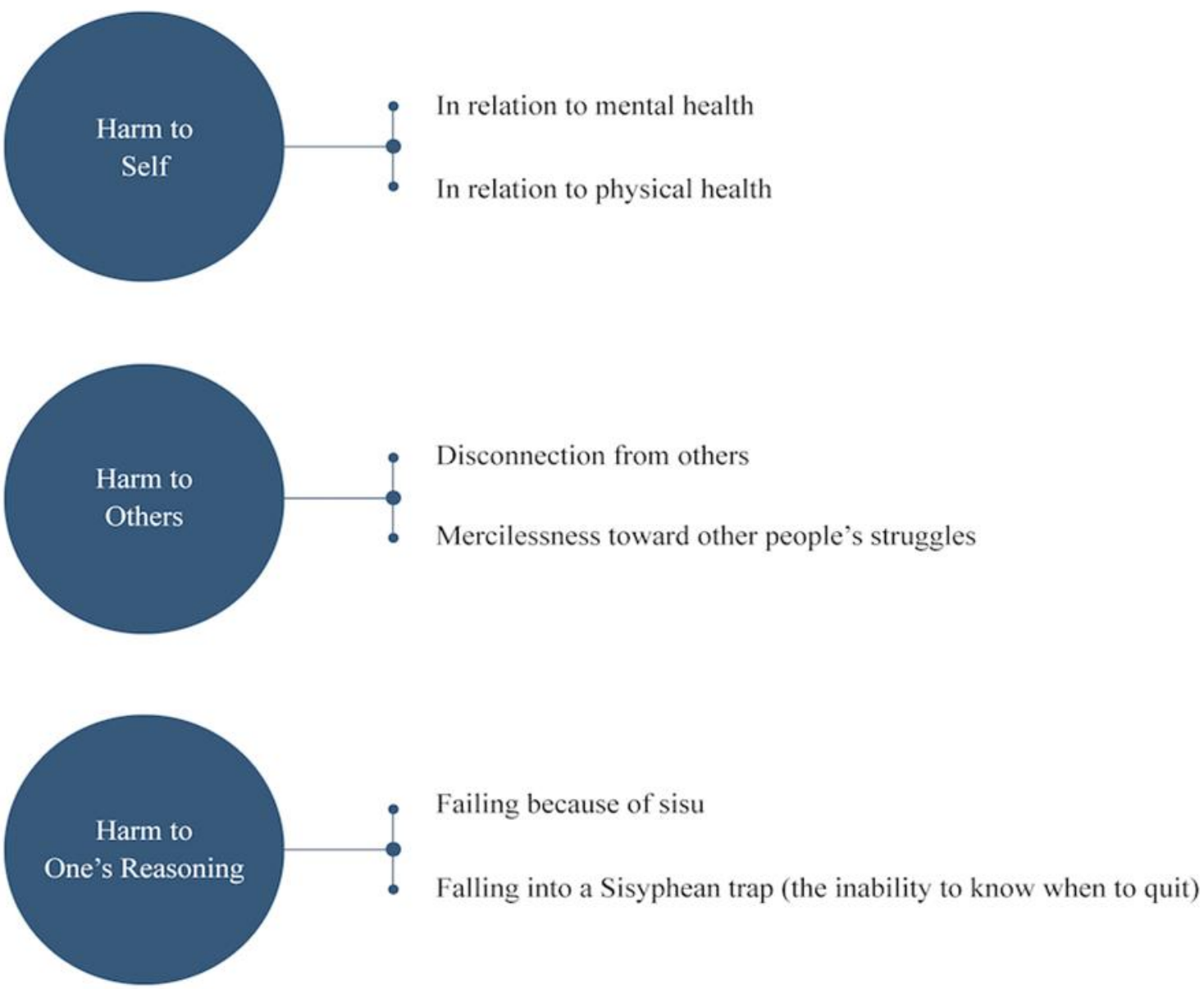

Theme 3. Harm to reasoning. Too much sisu can cloud the mind and lead to opposite results than what were intended (Table 6). Examples include: having poor judgment, getting fixated on goals that may not work in the long run or may be harmful, and not being able to see the big picture or evaluate one's capacities and ask for help. Too much sisu could lead to not knowing when to quit (and not quitting when knowing that one should quit), therefore leading the individual in a 
pointless loop of repeating the same pattern and expecting different results. The legend of Sisyphus, who, according to the Ancient Greek story, is stuck in futile labour of rolling a heavy boulder up a steep hill, only to see it roll back down, is perhaps an apt metaphor for this. Failure because of sisu ended up being a subtheme under "harm to reasoning," since it was most often mentioned in relation to impaired thinking. The following response points to reasoning as a cornerstone of constructive sisu:

You need to focus clearly on what you are now, but you also need to be able to learn from the past and be creative in finding new solutions when you seem to be stuck, knowing that hard work will pay off in the end.

\section{Table 4. Harm to self: Codes and examples}

\begin{tabular}{|c|c|c|c|}
\hline $\begin{array}{l}\text { Harm to self } \\
\text { Harm to mental or } \\
\text { physical health and } \\
\text { wellbeing as a result of } \\
\text { trying too hard, being } \\
\text { foolhardy, stubborn or } \\
\text { reckless. }\end{array}$ & $\begin{array}{l}2.1 \\
2.2 \\
2.3 \\
2.4 \\
2.5 \\
2.6 \\
2.7 \\
2.8\end{array}$ & $\begin{array}{l}\text { Injury } \\
\text { Loss of health } \\
\text { Burnout and exhaustion } \\
\text { Accidents } \\
\text { Death } \\
\text { Taking on too much } \\
\text { responsibility } \\
\text { Making unhealthy } \\
\text { sacrifices } \\
\text { Taking foolhardy risks }\end{array}$ & $\begin{array}{l}\text { "Going beyond your c apacities in a negative way } \\
\text { with the pow er of sisu: losing w eight and } \\
\text { becoming anorexic or an athlete practicing so } \\
\text { hard they become badly injured." } \\
\text { "Over-exhaustion, burn-out ... in worst case } \\
\text { death." } \\
\text { "Taking foolish risks and ending up in a } \\
\text { hospital." } \\
\text { "Disappointments and bitterness. Sometimes } \\
\text { things just don't go exactly the way you want." } \\
\text { "Overtaxing mental reserves may cause mental } \\
\text { trauma, foolhardiness in the physical domain can } \\
\text { even cause death." }\end{array}$ \\
\hline
\end{tabular}

Table 5. Harm to others: Codes and examples

\begin{tabular}{|c|c|c|}
\hline $\begin{array}{l}\text { Harm to others } \\
\text { Harm to other people } \\
\text { within close proximity } \\
\text { of the individual or the } \\
\text { community as a result } \\
\text { of becoming } \\
\text { disconnected and } \\
\text { blinded by one's own } \\
\text { sisu or personal goals. }\end{array}$ & $\begin{array}{ll}2.9 & \text { Ignorance } \\
2.10 & \text { Overriding other } \\
\text { people's opinions } \\
\text { 2.11 } \\
\text { 2.12 Peing unmerciful } \\
\text { 2.13 Self-righteousness } \\
\text { 2.14 Damage to relationships } \\
\text { 2.15 Arguments/conflicts } \\
\text { 2.16 Inability to attune to } \\
\text { people's needs } \\
2.17 \text { Harm to team work }\end{array}$ & $\begin{array}{l}\text { "It's not necessarily the person with sisu who will } \\
\text { become depleated [sic] but the people around the } \\
\text { person." } \\
\text { "A person or a group with [unhealthy] sisu is } \\
\text { ruthless and selfish. This kind of a person has } \\
\text { taught herself to finish things but may not be the } \\
\text { best team player. She will work hard for her } \\
\text { family or community but with no consideration to } \\
\text { others." } \\
\text { "Sucking out the energy from other people and } \\
\text { nevertheless, ending up exhausted." } \\
\text { "Too much focusing on a specific task, neglecting } \\
\text { others' needs, requirements or sensibilities. } \\
\text { Examples: a man building a house alone, } \\
\text { neglecting his health, family and friends. A } \\
\text { soldier, chock-full of sisu, trying to destroy an } \\
\text { enemy emplacement, abandoning his squad and } \\
\text { brothers in arms for a feat of personal glory." }\end{array}$ \\
\hline
\end{tabular}


Table 6. Harm to reasoning: Codes and examples

\begin{tabular}{|c|c|c|}
\hline $\begin{array}{l}\text { Harm to reasoning } \\
\text { Inability to reason, } \\
\text { think logically and use } \\
\text { constructive cognitive } \\
\text { strategies to ensure a } \\
\text { successful outcome. } \\
\text { Becoming blind to the } \\
\text { situation, having a } \\
\text { fixed mindset and } \\
\text { prioritizing short-term } \\
\text { gains over long-term } \\
\text { success. }\end{array}$ & $\begin{array}{l}\text { 2.18 Failure to know when to quit } \\
\text { 2.19 Inability to reason } \\
\text { 2.20 Inability to see a situation } \\
\text { for what it is } \\
\text { 2.21 Stubbornness that nears } \\
\text { senselessness } \\
\text { 2.22 Functioning from fear mode } \\
\text { 2.23 Inability to take advice } \\
\text { or ask for help } \\
\text { 2.24 Inability to learn } \\
\text { 2.25 Poor judgment } \\
\text { 2.26 Getting stuck in a rut } \\
\text { ("The Sisyphean trap") }\end{array}$ & $\begin{array}{l}\text { "You can lose things if you don't admit you're } \\
\text { wrong, or there's nothing you can do about } \\
\text { something" } \\
\text { "Not knowing when to quit even though you will } \\
\text { never succeed; spending too much time on } \\
\text { unnecessary pursuit that doesn't really even give } \\
\text { you a reward." } \\
\text { "When sisu itself become the goal, you're already } \\
\text { in trouble. Sisu should always be a means to an } \\
\text { end and even then one which is used with } \\
\text { consideration." } \\
\text { "You can lose sight of what you are doing and } \\
\text { not see the big picture." } \\
\text { "Arrogance. Blindness. Failure to reevaluate } \\
\text { oneself or one's approach. Failure to experiment. } \\
\text { Failure to listen." }\end{array}$ \\
\hline
\end{tabular}

\section{Discussion}

Three themes describing the essence of sisu were generated as a result of a thematic analysis. While each theme presents a separate narrative, they are all more or less about finding a way to keep on moving forward when the external evidence and internal emotional feedback might point to the contrary.

Extraordinary perseverance relates to overcoming hardships and exceeding our preconceived limits, to venture beyond the known edges of our strength and transform assumed barriers into frontiers. Action mindset is a forward-leaning, active approach toward challenges that acts as a pathway to taking action. Latent power is our "inner engine" and denotes reserves of stored-up energy, which ordinarily are not called upon but are available when an unusually demanding situation occurs. Latent power echoes the etymological origin of sisu that literally translates as "innermost part" or the "guts," and, while doing so, it touches upon the elusive phenomenon, often described as human spirit or life force, that has piqued the minds of scientists, philosophers, storytellers, and artists alike across millennia. In the words of one respondent, "[Sisu] is what defines us and is almost like magic in the sense that with it, you can do what others think is not possible."

Extraordinary perseverance and action mindset incorporate nuances from related psychological concepts such as courage, perseverance and grit, while latent power points to something visceral rather than mental, and proposes a potential connection to research within embodied and somatic sciences.

\subsection{Sisu and related constructs}

In the empirical section of this article, sisu was analysed as a cultural construct. I propose that it not only enriches our shared vocabulary of the human experience by introducing a word outside the mainstream of American psychological lexicon, but points to a real phenomenon for which no term has existed. In the following, I briefly compare sisu to some related constructs. 
Whereas perseverance is the steadfast pursuit of a task, despite encountering obstacles and discouragement, with its emphasis on endurance measured by duration and consistency (Markman, Baron, \& Balkin, 2005), grit involves passion and its transformation into perseverance (Duckworth, Peterson, Matthews, \& Kelly, 2007). One of the core components of grit is a sense of goal orientation, a pursuit of a dominant superordinate life goal (Duckworth \& Gross, 2014). Though "being gritty" and persevering means to keep on going despite adversities along the way, it does not necessarily require a singular adverse incident to initiate it (Collins, MacNamara, \& McCarthy, 2016).

The most pronounced quality of sisu relates to overcoming adversity, discomfort, and challenges. In the data, it was rarely described in relation to the pursuit of goals. Sisu overlaps with certain endurance aspects of perseverance and grit but differs in its emphasis on short-term intensity rather than long-term stamina. Most of the examples of sisu in the data involved determination and doggedness typical of grit but without the passion or focus for a big, overarching life goal. Sisu is less about passion, achievement and winning (although it definitely can relate to those situations as well) and more about "putting up a good fight" and giving something everything you have. Grit and perseverance get us on the road and keep us going long. Sisu is the spare tank of fuel we tap into when we find ourselves running on empty.

While there is no one universal definition of courage, researchers have been making progress in separating several different types of courage. The common thread between all of them is acting despite some form of fear (e.g., Norton \& Weiss, 2009; Rachman, 1990), whether it is, e.g., fear of judgment, social exclusion, unfavorable consequences, pain or physical harm. Even though acting courageously in a particular situation means having to overcome fear, it may not always require going above and beyond one's observed resources and therefore, tapping into "sisu zone." Consequently, while courage as a construct was not a main narrative in the data, facing and overcoming one's fears was part of the theme of action mindset.

Psychological resilience is defined as positive adaptation to tragedy or ongoing significant life stressors (Luthar, Cicchetti, \& Becker, 2000), and the ability to bounce back from hardship (Tugade \& Fredrickson, 2004). It is increasingly viewed as a dynamic process in which learned coping methods and psychological strategies such as optimism, problem solving, self-efficacy, and emotion regulation play a role (Luthar, Cicchetti, \& Becker, 2000; Reivich \& Shatte, 2002). Hardiness was originally researched as a pathway to resilience and is described as a combination of three separate but interrelated attitudes of commitment, control, and challenge (3Cs) (Kobasa, 1979; Maddi \& Kobasa, 1984).

Mental toughness is an umbrella term used rather liberally to refer to sport-specific and sport-general values, attitudes, behaviours, and emotions that enable the individual to persevere, overcome an obstacle, and manage pressure (Gucciardi, Gordon, \& Dimmock, 2008, 2009). Similarly to resilience, it is viewed as a collection of developed and inherent strategies and mental qualities. Sisu is proposed as one pathway to resilience; it may contribute to an individual's ability to retain the commitment and control required for hardiness, and allow for the final push of an athlete approaching the end of her known capacities. "Sisu is a state of body, mind, heart, and soul in which you will not give up, no matter what comes your way. It is brother to 'grit' and sister to 'perseverance' and it will carry you through thick and thin" (a quote from the data).

There is a degree of overlap likely between all constructs that seek to explain how humans keep on going. One can theorise where one begins and the other ends, but, in practice, it is hard to draw such lines and most likely we do not need to. However, in a culture that obsesses about the power of the mind, sisu takes a different turn. It invites us to pay attention to the potentially embodied quality of courage and fortitude. Sisu as latent power points to a source of endurance 
that is more about the visceral and somatic than conscious and cognitive, and which we know relatively little about: the embodied determinants of human emotion and functioning.

\subsection{Embodied fortitude: Accessing reserves of latent energy}

The most prominent narrative around the conceptual core of sisu is the ability to surpass one's preconceived limitations by accessing stored up deep energy reserves. While triumphing against slim odds and overcoming adversity are ubiquitous in our collective stories of human endurance, the phenomenon has been notoriously hard to explain, and scattered research exists. Psychologist and philosopher William James was piqued by the phenomenon a century ago:

For many years I have mused on the phenomenon of second wind, trying to find a physiological theory. It is evident that our organism has stored-up reserves of energy that are ordinarily not called upon, but that may be called upon: deeper and deeper strata of combustible or explosible material, discontinuously arranged, but ready for use by anyone who probes so deep... (James, 1914, p. 8).

Given the acquired understanding of sisu as a latent source of energy, in this section, I aim to examine how such a construct could be related to certain psychological and biological processes that have emerged from recent research. Research on the physiological side of stored-up capacity comes from the world of diving, weightlifting and competitive sports. Free divers, for example, are able to far surpass the limits of ordinary breath holding because of a mechanism that causes the spleen to contract and change the diver's blood composition by releasing oxygenated red blood cells into the bloodstream. Studies on the biomechanics of weightlifting show that humans who are untrained are usually able to tap into about $65 \%$ of their maximal strength, the maximum a person could lift using conscious effort, while for trained weightlifters, this number is about $80 \%$ (Zatsiorsky \& Kraemer, 2006). The adrenal glands pump cortisol and adrenaline into the blood stream, preparing the body for the surge of energy needed for the fight-or-flight response.

It seems that the threshold of exceeding our capacities is not fixed but can be influenced. In a 2008 study, Pollo, Carlino and Benedetti found that subjects who were given a placebo but told it was caffeine were able to lift more weight. Clark, Hopkins, Hawley, and Burke (2000) discovered a similar effect in a simulated $40-\mathrm{km}$ bicycle time trial. The placebo effect has also been illustrated for pain and movement disorders (Amanzio \& Benedetti, 1999; Pollo, Carlino, \& Benedetti, 2011), and there is evidence to suggest that the effect is related to individuals' expectations and beliefs. Amanzio \& Benedetti (1999) showed that placebo analgesia (pain relief) could be induced with verbal suggestions and Dweck's decades of research on mindset suggest that the beliefs individuals hold about their abilities impact their future behavior and even willpower (Job, Dweck, \& Walton, 2010; Yeager \& Dweck, 2012).

Endurance can also be viewed as tolerance to muscle fatigue. According to the central governor theory (CGT) this is an emotional event (not a physical one) in which the brain "shuts off the body" to prevent hurt (Noakes, St. Clair Gibson, \& Lambert, 2004). Marcora's research challenges this long-held notion by suggesting that exercise tolerance is ultimately limited by our perception of effort weighed against our motivation, not muscle fatigue or the capability of the muscles (Marcora \& Staiano, 2010). Even after exerting themselves to the point of exhaustion either physically or mentally, research participants were able to exert themselves more if sufficiently motivated (Boksem, Meijman, \& Lorist, 2006; Marcora \& Staiano, 2010). A study by Job, Dweck and Walton (2010) showed that research participants who believed that their willpower is limited and fixed were more likely to give up than those who believed that willpower is self-renewing. 
Latent power, or "intestinal fortitude," as described by one respondent, is about fortitude as a somatic quality. Research examining the embodied nature of human behavior and decision making has been overshadowed by the notion of behaviors emanating solely from the mind. In the last few decades, an idea has been promoted in cognitive science to view the body as having a central role in shaping our mind, actions and emotions. Embodied cognition has now been fairly well established and it is the radical hypothesis that "our bodies and their perceptually guided motions through the world do much of the work required to achieve our goals" (Wilson \& Golonka, 2013).

Furthermore, the expression of sisu is perhaps not entirely separate from its environment. After all, it is often called into being through the dynamic ebb and flow of situations that require us to act and respond. Competition, fear or crises, but also a deep sense of purpose or fighting for a cause deemed worthy (the latter illustrated throughout the history of social justice by people from Rosa Parks and Nelson Mandela to Edward Snowden, and the like), can open a window to highly unusual displays of courage and emotional endurance. Having a self-transcendent or prosocial purpose improves self-regulation in academic settings during tedious learning activities (Yeager et al., 2014) and it has also been linked to positive outcomes for individuals surviving breast cancer (Matthews \& Cook, 2009), to liver transplant recipients (Wright, 2003), and AIDS patients (Ramer, Johnson, Chan, \& Barrett, 2006). Half a century earlier, Austrian psychiatrist Viktor Frankl (1963) chronicled his extreme experiences as an Auschwitz concentration camp inmate and identified that those who survived the inhumane conditions almost always had a self-transcendent purpose in their lives. For Frankl himself, this meant enduring countless beatings, digging frozen ground, and fighting off malnutrition for years in the hopes of being reunited with his loved ones.

Six decades ago, Roger Bannister became the first person to run a mile in under four minutes. A deed long deemed impossible and even dangerous has since been lowered by almost 17 seconds and is now the standard of all male professional middle distance runners. It appears that either our capacities are still far from being set or our level of knowledge about the determinants of human performance is simply inadequate and could benefit from more systematic, crossdisciplinary research. Our bodies and minds are not limitless, but the extent of those limits seems negotiable, with many paths leading to the top of "Mount Sisu".

\subsection{What doesn't kill us makes us stronger, until it doesn't: On embracing constructive sisu}

Encountering adversities emerged as a subcategory within the theme of extraordinary perseverance. While defining adversity can be a slippery slope, since what qualifies as a threshold of discomfort varies between individuals (DeLongis, Coyne, Dakof, Folkman, \& Lazarus, 1982), in this paper it is approached simply from the angle of subjective human experience. What is considered to be the threshold of "significant challenge" is determined by the individual and varies between individuals, as well as within an individual's lifespan, as we transform our life's barriers into frontiers and render the unknown areas of our abilities into known ones. According to the survey, adversity seems to act as the doorway to sisu; sometimes it is the very experience of stress and discomfort that unleashes potentialities we did not necessarily know existed, a perspective that corresponds to certain psychological theories. Below is another excerpt from Energies of Men:

If an unusual necessity forces us to press onward, a surprising thing occurs. The fatigue gets worse up to a certain critical point, when gradually or suddenly it passes away, and we are fresher than before. We have evidently tapped a level of new energy, masked until then by the fatigue-obstacle usually obeyed. There may 
be layer after layer of this experience. A third and a fourth "wind" may supervene (James, 1914, p. 7).

Following this logic, we find sisu, our "second wind" and the extent of our mental and bodily strength, not despite adversities and discomfort, but because of them. Akin to photosynthesis in nature, which is the complex process of transforming light energy into chemical energy, there seems to exist an equally puzzling process through which humans unearth and transform their latent energy into movement, momentum and action during moments which at first seem but dead ends. Luthar, Cicchetti and Becker (2000) argue that in order to become resilient, an individual must experience some hardship. However, no tree grows infinitely into the sky. Hardships strengthen the individual but after a certain point the impact can be the opposite (Brown et al., 2009; van der Kolk, 2000). What doesn't kill us makes us stronger, until it doesn't. The idea is not to view adversities as entirely negative events but as a pathway to strength which we might not otherwise experience. Tedeschi and Calhoun's (2004) work on posttraumatic growth shows that adversity can be a powerful catalyst for positive, life-altering changes in an individual's life.

If having sisu helps individuals endure, does more sisu always mean more endurance? According to these data the answer is no, and too much sisu may impair our ability to think clearly. It is not simply a matter of quantity (and whether one has it or not) but the quality of sisu, and perhaps also, of our thinking. In the broader scheme of things, our sisu is as good as our ability to reason, make informed decisions, attune to our surroundings, and evaluate our actions. At worst, the very quality that could elevate a person beyond her wildest dreams can be the thing to destroy her.

The discussion on sisu extends far beyond the individual, as the impacts of our behavior influence those around us. The majority of respondents were keen to acquire more sisu, but were concerned how one can know if it's wiser to continue to endure, or to simply give up. According to the data, too much sisu can result in disconnection from others and create an attitude of mercilessness as the individual imposes his or her own high (or harsh) standards on others. It seems that sisu is neither good nor bad, but is a tool one must learn to master.

While endurance is about cultivating the emotional and physical stamina to endure life's curve balls, one must also strive to become a well-rounded thinker, who is able to assimilate information from the surrounding environment and respond to challenges in a healthy way. Constructive sisu is not blind and obsessive but flexible, adaptive and is informed by reason. It can also mean acceptance, surrender, and finding contentment in the moment instead of fighting it. This notion aligns with research by Vallerand et al. (2003) on the two types of passion for activities. "Whether a passion will foster positive affect and healthy persistence depends on whether it is harmonious or obsessive" (p. 757). While challenges can act as a pathway to sisu and growth, reasoning and self-understanding are the lamp to guide our steps.

\subsection{Limitations of the study and future work}

While the research helps render a more nuanced understanding of sisu, it nevertheless supports the notion of sisu as a construct that is hard to explain. Out of the three themes describing the main essence of sisu, the third, latent power, leaves us with more questions than answers. This may be partly because the language and research for examining the embodied nature of human emotion and cognition have been overshadowed by the notion of behaviors emanating solely from the mind. The survey did not offer a deep enough dive into the construct, and descriptions such as "hard to describe" and "magical quality" were commonplace. However, it offers signposts that help inform the next set of research questions. Future studies may benefit from 
having a more in-depth approach and conducting unstructured interviews within the various domains in which humans encounter and overcome adversity. Finally, it is important to note that $80 \%$ of the survey respondents were women, and in future studies it would be preferable to aim for a more balanced sample.

Whereas the present study offers a preliminary outline of the relationship between sisu and related qualities, further research is needed to understand how these qualities may influence one another, whether sisu can be cultivated, and, if so, how. Furthermore, is sisu an enduring response of an individual that extends across situations or is it a more situation- or task-specific outcome? Is there a difference in the sisu-response between self-selected challenges and ones that people are forced to react to?

While Finland is recognised as the home of the construct of sisu, stories of humans extending beyond their known capacities are weaved into the collective daily canvas and history of our entire species. A systematic examination of stories and words from other cultures, such as rasmia (Spanish), gaman (Japanese) and l'chatchila ariber (Aramaic) that relate to overcoming adversity, could further deepen our knowledge of the phenomenon. Finally, the growing body of research on the role of the enteric nervous system and gut bacteria in emotion regulation can offer yet another fascinating pathway to understanding fortitude in a more holistic way.

\section{Conclusion}

The study introduced the Finnish cultural construct of sisu by exploring its representations among the Finnish population through a thematic analysis. Sisu shares overlapping features with psychological qualities such as courage, perseverance and grit, but its most pronounced aspect is about tapping into previously unknown energy reserves that seem partially embodied rather than purely mental.

Stories of sisu are stories about transcending limitations across all domains of human life, from the physical to the emotional. It lends a word to the universal capacity of humans everywhere to endure in the face of adversity and take action against nearly impossible odds when needed. However, when discussing human behavior, we are dealing with a multifaceted phenomenon, which should not be merely reduced to its prominent characteristics. Too much sisu can lead to stubbornness, disconnection, and other potentially harmful outcomes. Sisu can be either self-defeating or self-enhancing, and understanding the conditions for both is crucial if one wishes to explore how it may be developed on an individual and collective level. A culture that glorifies and worships mental toughness, sisu, and achievement at the expense of virtues such as justice, benevolence, and integrity, puts itself on a dangerous path towards a world that demands winners and disregards those who can't or choose not to fit this mould.

Language gives birth to mental imagery and constructs that help us describe our experiences and the world we live in. There are lessons to be learned in all cultures about how humans persevere. Rendering something from "untranslatable" into a description which communicates meaning, can bring it within people's grasp and open a possibility for empowering new dialogues. As we grow in our understanding of the phenomenon outlined in this paper-one that draws from a multitude of disciplines and ideas - we can unlock tools to address William James' century-old question pertaining to the extent and limits of human spirit, while doing so, perhaps stirring the waters around the grand mystery of life itself: what is it that keeps our lights burning and hearts hoping during the dark night of the soul, and how might we best use this knowledge to alleviate the pain of those who are currently suffering? 


\section{Acknowledgments}

A smile of gratitude to my advisors Esa Saarinen and Frank Martela, and all the kind reviewers, who gifted their invaluable feedback to improve this article. To Angela Duckworth for inspiration and support along the journey, and to my friends and family, who saw me through this writing process, which, at times, in itself felt like a feat of sisu.

\section{Author}

Emilia Elisabet Lahti

Aalto University, Espoo

emilia.lahti (at) aalto.fi

\section{Publishing Timeline}

Received 8 September 2017

Accepted 11 November 2018

Published 3 April 2019

Corrected version published 12 October 2022 (fixed the number of answers to questions about sisu)

\section{References}

Aho, W. R. (1994). Is sisu alive and well among Finnish Americans? In M. G. Karni \& J. Asala (Eds.), The best of Finnish americana (pp. 196-205). Iowa City, IA: Penfield Press.

Amanzio M., \& Benedetti F. (1999). Neuropharmacological dissection of placebo analgesia: Expectationactivated opioid systems versus conditioning-activated specific sub-systems. Journal of Neuroscience, 19(1), 484-494. https://doi.org/10.1523/INEUROSCI.19-01-00484.1999

Anthes, E. (2016, May 12). The glossary of happiness. The New Yorker. https://www.newyorker.com/tech/annals-of-technology/the-glossary-of-happiness

Attride-Stirling, J. (2001). Thematic networks: An analytic tool for qualitative research. Qualitative Research, 1(3), 385-405. https://doi.org/10.1177/146879410100100307

Bermant, G., Talwar, C., \& Rozin, P. (2011) To celebrate positive psychology and extend its horizons. In K. M. Sheldon, T. B. Kashdan, \& M. F. Steger (Eds.), Designing positive psychology: Taking stock and moving forward (pp. 430-438). Oxford, England: Oxford University Press. https://doi.org/10.1093/acprof:oso/9780195373585.003.0029

Boksem, M. A. S., Meijman, T. F., \& Lorist, M. M. (2006). Mental fatigue, motivation and action monitoring. Biological Psychology, 72(2) 123-132. https://doi.org/10.1016/j.biopsycho.2005.08.007

Boyatzis, R. (1998). Transforming qualitative information: Thematic analysis and code development. Thousand Oaks, CA: Sage.

Braun, V., \& Clarke, V. (2006). Using thematic analysis in psychology. Qualitative Research in Psychology, 3(2), 77-101. https://doi.org/10.1191/1478088706qp063oa

Braun, V., \& Clarke, V. (2016). Thematic analysis. In E. Lyons \& A. Coyle (Eds.), Analysing qualitative data in psychology (2nd ed., pp. 84-103). London, England: Sage.

Brown, D. W., Anda, R. F., Tiemeier, H., Felitti, V. J., Edwards, V. J., Croft, J. B., Giles, W. H. (2009). Adverse childhood experiences and the risk of premature mortality. American Journal of Preventive Medicine, 37(5), 389-396. https://doi.org/10.1016/j.amepre.2009.06.021

Clark, V. R., Hopkins, W. G., Hawley, J. A., \& Burke, L. M. (2000). Placebo effect of carbohydrate feedings during a 40-km cycling time trial. Medicine $\mathcal{E}$ Science in Sports \& Exercise, 32(9), 1642-1647. https://doi.org/10.1097/00005768-200009000-00019

Collins D., MacNamara, A., \& McCarthy, N. (2016). Super champions, champions, and almosts: Important differences and commonalities on the rocky road. Frontiers in Psychology, 6, 1-11. https://doi.org/10.3389/fpsyg.2015.02009 
DeLongis, A., Coyne, J. C., Dakof, G., Folkman, S., \& Lazarus, R. S. (1982). Relationship of daily hassles, uplifts, and major life events to health status. Health Psychology, 1(2), 119-136. https://doi.org/10.1037/0278-6133.1.2.119

Duckworth, A. L., \& Gross, J. J. (2014). Self-control and grit: Related but separable determinants of success. Current Directions in Psychological Science, 23(5), 319-325. https://doi.org/10.1177/0963721414541462

Duckworth, A. L., Peterson, C., Matthews, M. D., \& Kelly, D. R. (2007). Grit: Perseverance and passion for long-term goals. Journal of Personality and Social Psychology, 92(6), 1087- 1101. https://doi.org/10.1037/0022-3514.92.6.1087

Dweck, C. S. (2006). Mindset: The new psychology of success. New York, NY: Random House.

Finland: Nothing Worse to Fear (1943, May 10). Time Magazine. http://content.time.com/time/magazine/article/0,9171,851579,00.html

Frankl, V. E. (1963). Man's search for meaning. New York, NY: Washington Square Press.

Fusch, P. I., \& Ness, L. R. (2015). Are we there yet? Data saturation in qualitative research. The Qualitative Report 20(9), 1408-1416. https://nsuworks.nova.edu/cgi/viewcontent.cgi?article=2281\&context=tqr

Gosling, J., \& Mintzberg, H. (2003). The five minds of a manager. Harvard Business Review, 81(11), 54-63. https://www.ncbi.nlm.nih.gov/pubmed/14619151

Green, J., \& Thorogood, N. (2004). Qualitative methods for health research. London, England: Sage.

Gucciardi, D., Gordon, S., \& Dimmock, J. (2008). Towards an understanding of mental toughness in Australian football. Journal of Applied Sport Psychology, 20(3), 261-281. https://doi.org/10.1080/10413200801998556

Gucciardi, D., Gordon, S., \& Dimmock, J. (2009). Advancing mental toughness research and theory using personal construct psychology. International Review of Sport and Exercise Psychology, 2(1), 54-72. https://doi.org/10.1080/17509840802705938

Guest, G., Bunce, A., \& Johnson, L. (2006). How many interviews are enough? An experiment with data saturation and variability. Field Methods, 18(1), 59-82. https://doi.org/10.1177/1525822X05279903

Guest, G., MacQueen, K. M., \& Namey, E. E. (2012). Applied thematic analysis. Thousand Oaks, CA: Sage. https://doi.org/10.4135/9781483384436

Hintikka, K. A. (1998). Puheenvuorojen kirjasto: Keskustelua suomalaisesta tietoyhteiskunnasta. Helsinki: Sitra. [Library of speeches: Discussions on the Finnish information society] https://www.sitra.fi/julkaisut/puheenvuorojen-kirjasto/

James, W. (1914). The energies of men. New York, NY: Moffat, Yard and Company.

Job, V., Dweck, C. S., \& Walton, G. M. (2010). Ego depletion - Is it all in your head? Implicit theories about willpower affect self-regulation. Psychological Science, 21(11), 1686-1693. https://doi.org/10.1177/0956797610384745

Jones, G., Hanton, S., \& Connaughton, D. (2007). A framework of mental toughness in the world's best performers. The Sport Psychologist, 21(2), 243-264. https://doi.org/10.1123/tsp.21.2.243

Kobasa, S. C. (1979). Stressful life events, personality, and health: Inquiry into hardiness. Journal of Personality and Social Psychology. 37(1), 1-11. https://doi.org/10.1037/0022-3514.37.1.1

Länsimäki, M. (2003, March 11). Suomalaista sisua [Finnish sisu]. Helsingin Sanomat.

Lomas, T. (2016). Towards a positive cross-cultural lexicography: Enriching our emotional landscape through 216 'untranslatable' words pertaining to well-being. The Journal of Positive Psychology, 11(5), 546-558. http://doi.org/10.1080/17439760.2015.1127993

Lucas K., \& Buzzanell, P. M. (2004). Blue-collar work, career, and success: Occupational narratives of sisu. Journal of Applied Communication Research, 32(4), 273-292. https://doi.org/10.1080/0090988042000240167

Luthar, S. S., Cicchetti, D., \& Becker, B. (2000). The construct of resilience: A critical evaluation and guidelines for future work. Child Development, 71(3), 543-562. https://doi.org/10.1111/1467-8624.00164

Maddi, S. R. (2004). Hardiness: An operationalization of existential courage. Journal of Humanistic Psychology, 44(3), 279-298. https://doi.org/10.1177/0022167804266101

Maddi, S. R. (2006). Hardiness: The courage to grow from stresses. Journal of Positive Psychology, 1(3), 160168. https://doi.org/10.1080/17439760600619609 
Maddi, S. R., \& Kobasa, S. C. (1984). The hardy executive: Health under stress. Homewood, IL: Dow JonesIrwin.

Marcora, S. M., \& Staiano, W. (2010). The limit to exercise tolerance in humans: Mind over muscle? European Journal of Applied Physiology, 109(4), 763-770. https://doi.org/10.1007/s00421-010-1418-6

Markman, G. D., Baron, R. A., \& Balkin, D. B. (2005). Are perseverance and self-efficacy costless? Assessing entrepreneurs' regretful thinking. Journal of Organizational Behavior, 26(1), 1-19. https://doi.org/10.1002/job.305

Matthews, E. E., \& Cook, P. F. (2009). Relationships among optimism, well-being, self-transcendence, coping, and social support in women during treatment for breast cancer. Psycho-Oncology, 18(7), 716726. https://doi.org/10.1002/pon.1461

Miles, M. B., \& Huberman, A. M. (1984). Qualitative data analysis: A sourcebook of new methods. Newbury Park, CA: Sage.

Namey, E., Guest, G., Thairu, L., \& Johnson, L. (2007). Data reduction techniques for large qualitative data sets. In G. Guest \& K. M. MacQueen (Eds.), Handbook for team-based qualitative research (pp. 137161). Plymouth, England: AltraMira Press.

Noakes, T. D., St. Clair Gibson, A., \& Lambert, E. V. (2004). From catastrophe to complexity: A novel model of integrative central neural regulation of effort and fatigue during exercise in humans. British Journal of Sports Medicine, 38(4), 511-514. https://doi.org/10.1136/bjsm.2003.009860

Norton, P. J., \& Weiss, B. J. (2009). The role of courage on behavioral approach in a fear-eliciting situation: A proof-of-concept pilot study. Journal of Anxiety Disorders, 23(2), 212-217. https://doi.org/10.1016/j.janxdis.2008.07.002

Palo Stoller, E. (1996). Sauna, sisu, and Sibelius: Ethnic identity among Finnish Americans. The Sociological Quarterly, 37(1), 145-175. https://doi.org/10.1111/j.1533-8525.1996.tb02335.x

Peterson, C. (2008, September 17). Ikigai and mortality. Psychology Today. https://www.psychologytoday.com/intl/blog/the-good-life/200809/ikigai-and-mortality

Pinker, S. (2011). The better angels of our nature: Why violence has declined. New York, NY: Viking.

Pollo, A., Carlino, E., \& Benedetti, F. (2008). The top-down influence of ergogenic placebos on muscle work and fatigue. European Journal of Neuroscience, 28(2), 379-388. https://doi.org/10.1111/j.14609568.2008.06344.x

Pollo, A., Carlino, E., \& Benedetti, F. (2011). Placebo mechanisms across different conditions: from the clinical setting to physical performance. Philosophical Transactions of the Royal Society, 366(1572), 17901798. https://doi.org/10.1098/rstb.2010.0381

Pury, C. L. S., Kowalski, R. M., \& Spearman, J. (2007). Distinctions between general and personal courage. The Journal of Positive Psychology, 2(2), 99-114. https://doi.org/10.1080/17439760701237962

Pury, C. L. S., \& Lopez, S. J. (2009). The psychology of courage: Modern research on an ancient virtue. Washington, DC: American Psychological Association.

Rachman, S. J. (1990). Fear and courage (2nd ed.). New York, NY: W. H. Freeman and Company.

Ramer, L., Johnson, D., Chan, L., \& Barrett, M.T. (2006). The effect of HIV/AIDS disease progression on spirituality and self transcendence in a multicultural population. Journal of Transcultural Nursing, 17(3), 280-289. https://doi.org/10.1177/1043659606288373

Ramos, C., \& Leal, I. (2013). Posttraumatic growth in the aftermath of trauma: A literature review about related factors and application contexts. Psychology, Community \& Health, 2(1), 43-54. https://doi.org/10.5964/pch.v2i1.39

Reivich, K., \& Shatte, A. (2002). The resilience factor: 7 essential skills for overcoming life's inevitable obstacles. New York, NY: Random House.

Slade Lander, P. (1991). Finnish identity in a changing Europe. Ethnos 56(3-4), 242-255. https://doi.org/10.1080/00141844.1991.9981439

Strode, H. (1940, January 14). Sisu: A word that explains Finland. The New York Times Magazine, p. SM4. https://www.nytimes.com/1940/01/14/archives/sisu-a-word-that-explains-finland.html

Susag, C. (1998). Ethnic symbols: Their role in maintaining and constructing Finnish American culture. A brief history of the Finnish Americans in the Upper Midwest. Migration, 4, 3-8.

http://maine.utu.fi/articles/051 Susag.pdf 
Taramaa, R. (2007). Stubborn and silent Finns with 'sisu' in Finnish-American literature. An imagological study of Finnishness in the literary production of Finnish-American authors (Unpublished doctoral dissertation). University of Oulu, Oulu, Finland. http://jultika.oulu.fi/files/isbn9789514283734.pdf

Taramaa, R. (2009). Sisu as a central marker of Finnish-American culture: Stubbornness beyond reason. American Studies in Scandinavia, 41(1), 36-60. https://rauli.cbs.dk/index.php/assc/article/view/4624

Tedeschi, R. G., \& Calhoun, L. G. (2004). Posttraumatic growth: Conceptual foundations and empirical evidence. Psychological Inquiry, 15(1), 1-18. https://doi.org/10.1207/s15327965pli1501 01

Tuckett, A. G. (2005). Applying thematic analysis theory to practice: A researcher's experience. Contemporary Nurse, 19(1-2), 75-87. https://doi.org/10.5172/conu.19.1-2.75

Tugade, M. M., \& Fredrickson, B. L. (2004). Resilient individuals use positive emotions to bounce back from negative emotional experiences. Journal of Personality and Social Psychology, 86(2), 320-333. https://doi.org/10.1037/0022-3514.86.2.320

Vallerand, R. J., Blanchard, C., Mageau, G. A., Koestner, R., Ratelle, C., . . Marsolais, J. (2003). Les passions de l'âme: On obsessive and harmonious passion. Journal of Personality and Social Psychology, 85(4), 756-767. https://doi.org/10.1037/0022-3514.85.4.756

van der Kolk, B. (2000). Posttraumatic stress disorder and the nature of trauma. Dialogues in Clinical Neuroscience, 2(1), 7-22. https://www.ncbi.nlm.nih.gov/pmc/articles/PMC3181584

Wilson, A. D., \& Galonka, S. (2013). Embodied cognition is not what you think it is. Frontiers in Psychology, 4(58), 1-13. https://doi.org/10.3389/fpsyg.2013.00058

Wright, K. B., (2003). Quality of life, self-transcendence, illness distress, and fatigue in liver transplant recipients. (Unpublished doctoral dissertation). University of Texas at Austin, TX, USA. https://repositories.lib.utexas.edu/handle/2152/1082

Yeager, D. S, \& Carol S. Dweck, C. S. (2012). Mindsets that promote resilience: When students believe that personal characteristics can be developed. Educational Psychologist, 47(4), 302-314. https://doi.org/10.1080/00461520.2012.722805

Yeager, D. S., Henderson, M. D., Paunesku, D., Walton, G. M., D'Mello, S., Spitzer B. J., \& Duckworth, A. L. (2014). Boring but important: A self-transcendent purpose for learning fosters academic selfregulation. Journal of Personality and Social Psychology, 107(4), 559-580. https://doi.org/10.1037/a0037637

Zatsiorsky, V. M., \& Kraemer, W. J. (2006). Science and practice of strength training (2nd ed.). Champaign, IL: Human Kinetics. 


\section{Appendix A. Informed consent}

Dear participant,

You are being invited to participate in a research study examining the social representations of the Finnish concept of 'sisu'. To be able to answer the questions and take part in this survey requires that you are familiar with the construct of sisu. This survey is part of a master's thesis study for an applied positive psychology masters degree. Its aim is to contribute to the available research literature on sisu, as well as to create a platform for future research. The study also seeks to understand whether sisu can be cultivated through conscious training, and what benefits this yields for individuals as well as communities. The study is supervised by Angela Duckworth, Associate Professor of Psychology at the University of Pennsylvania.

In the following survey, you are requested to share your thoughts and personal experiences regarding sisu, and answer a few background questions. Very little empirical work has been done to explore the meaning of sisu. Your valuable input helps increase our general knowledge of the subject, and could potentially lead to the development of practical applications which enhance well-being.

All information provided will remain confidential, and will only be reported as group data with no identifying information. All data, including questionnaires, will be stored in a password protected electronic format and only those directly involved with the research will have access to it. There is no paid compensation for the survey, but you can choose to enter a draw to win a psychology-themed book.

Your participation in this study is completely voluntary. You may decline altogether, or leave blank any questions you do not wish to answer. Estimated participation time is about 15-20 minutes. Most of the yes / no options include space for your observations or comments. If you give the research team permission to be in contact with you (in case of any further questions), kindly add your email address at the end of the form. Your contact information will not be used for any purposes other than this study.

If you have any questions about this research project or experience technical difficulties filling out the survey, kindly contact Emilia Lahti [contact removed].

If you would like a copy of this consent form to keep for yourself, please print out this page before proceeding to the survey.

"By selecting 'yes' and proceeding to the questionnaire, I give my consent for my data to be used and published in a form in which I will not be personally identified."

No, I do not give my permission.

Leave the page.

Yes, I agree. Continue to the survey!

C

c

\section{Appendix B. Survey questions}

1. How would you define 'sisu'?

2. Which statement do you think better reflects the deepest essence of sisu?

3. What is the best thing about sisu or people who display sisu?

4. Do you believe some people inherently have more sisu than others?

5. Name a single person, group of people or nation whose actions reflect having sisu.

6. What kind of situations or life events cultivate sisu?

7. What circumstances or situations inhibit sisu?

8. Can sisu be learned or developed through conscious effort?

9. How would you advise cultivating the capacity for sisu?

10. Can an individual have too much sisu? 
11. What consequences there may be of having too much sisu?

12. Do you have sisu?

13. Do you wish you had more sisu?

14. How has having sisu affected your life? Kindly share an example.

15. How do other people's actions affect your sisu?

16. Would you rather a) choose to have more sisu or b) be more intelligent?

17. Would you be interested in cultivating sisu through conscious practice?

18. Do you have a favorite saying or quote about sisu?

19. Do you think the meaning of sisu has changed in the past hundred years?

20. In what ways do you think sisu or how we describe it has changed?

21. Do contemporary Finns have enough sisu?

22. How would future Finland look like, if Finns strived to increase their level of sisu?

23. Should there be more public discussion about sisu (in schools, workplaces and the media)?

Demographics:

24. What is your year of birth?

25. What is your gender?

26. What is the highest degree or level of school you have completed?

27. What is your marital status?

28. Number of children?

29. Total income of household?

30. Number of working adults in the household?

31. Are you a Finnish citizen?

32. How many years have you lived outside of Finland? 